Scientific Review - Engineering and Environmental Sciences (2019), 28 (1), 49-60

Sci. Rev. Eng. Env. Sci. (2019), 28 (1)

Przegląd Naukowy - Inżynieria i Kształtowanie Środowiska (2019), 28 (1), 49-60

Prz. Nauk. Inż. Kszt. Środ. (2019), 28 (1)

http://iks.pn.sggw.pl

DOI 10.22630/PNIKS.2019.28.1.5

Vyacheslav VISHNEVETSKIY ${ }^{1}$, Vladislav POPRUZHNIY ${ }^{2}$

${ }^{1}$ Southern Federal University

${ }^{2}$ Azovmorinformcenter

\title{
Investigations of the impact of polluted natural waters on cardiovascular diseases and development of integrated prevention system
}

Key words: primary morbidity, maximum permissible concentrations $(M P C)$, specific combinatorial water pollution index (SCWPI), critical indicators of water pollution

\section{Introduction}

Since the human body consists of water on more than $60 \%$, the health of the population directly depends on its quality. Each of our organs contains water: blood contains about $83 \%$ of water, the brain, heart, muscles - about $76 \%$ and even in bones contains not less than $15 \%$ of water. In order to preserve health, one should not allow body dehydration, because it can lead to thrombosis, cause a stroke, heart attack, sudden cardiac arrest. In view of the continuing anthropogenic impact on the aquatic environment, there exists an increasing negative impact of polluted natural waters on human health. It was revealed that the minimum amount of water that must be consumed by human body to stay healthy is $1.5 \mathrm{~L}$ per day. Thus the quality of water consumed by humans has a significant impact on the health of the population.

The most frequent cause of death is cardiovascular disease (CVD). Russia among the developed countries is the leader in this indicator. In Taganrog the highest mortality rates from these diseases in the Rostov region were registrated, the mortality rate exceeds the average regional rate by $1.2-1.3$ times. The percentage of the total number of deaths due to circulatory system diseases in Taganrog among men exceeds 50\%, among women is about $70 \%$. These diseases represent the greatest danger to public health in the Russian Federation and reduce life expectancy. In addition, in the long-term period increasing of mortality from CVD is observed: from $11 \%$ in 1939 , over $50 \%$ in the 1980 and about $60 \%$ in our time.

More than $70 \%$ of the drinking water in Taganrog comes from the main water 
intake in Kh. Rogozhkino at the mouth of the river Don (the sleeve of Kuterma), the rest water is taken in the additional point of water intake in Troitskoe on the river Mius (Vishnevetskiy \& Popruzhniy, 2015) as shown at Figure 1.
$(C O D)$; phenols; petroleum products; nitrites; nitrates; ammonium; chlorides; sulphates and heavy metals: iron, copper, nickel, manganese. Recommended list may further include any specific pollutant having local distribution in water

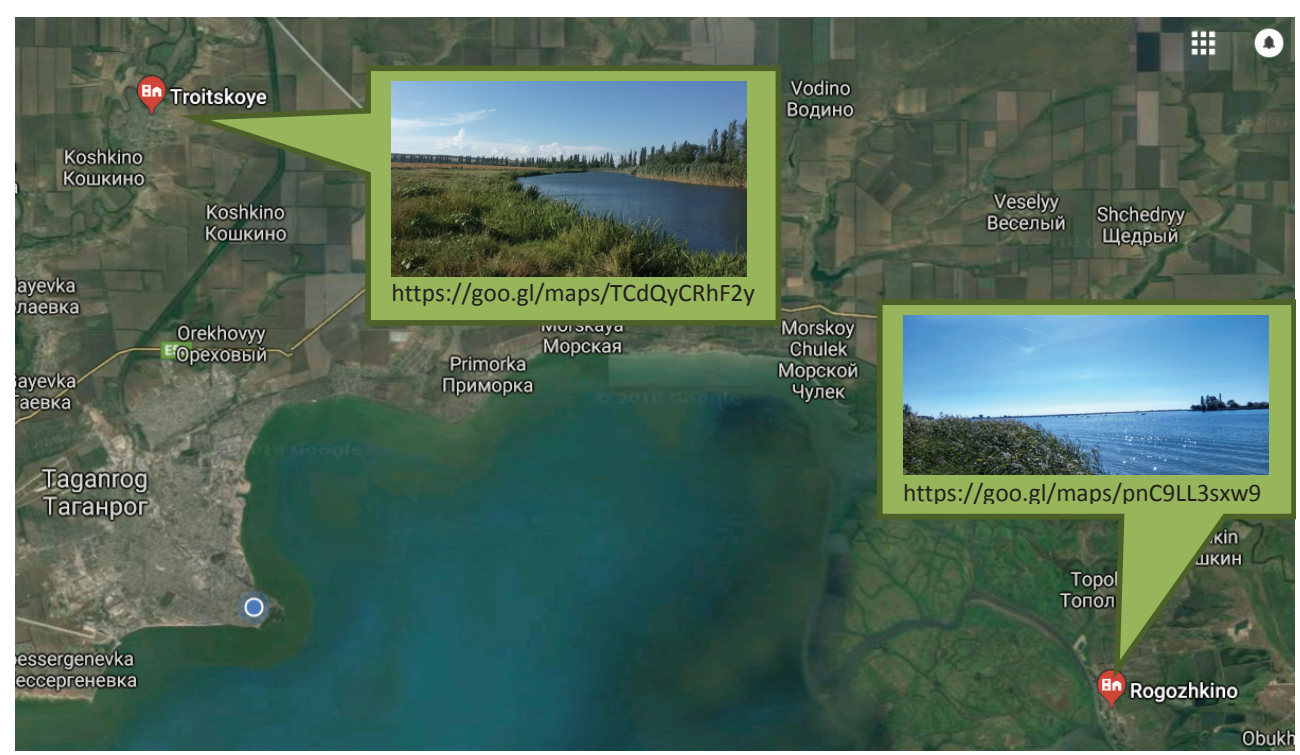

FIGURE 1. Points of water intakes (Federal Service for Supervision of Consumer Rights Protection and Human Welfare, 2014)

\section{Methods}

As a criterion of evaluation indicator of river water's quality the specific combinatorial index of water pollution $(S C W P I)$ is used in the Russian Federation. This comprehensive method of determining of natural water quality includes processing of information obtained as a result of monitoring of hydrochemical condition of the aquatic environment on the lists, including mandatory and recommended indicators. The mandatory list includes: dissolved oxygen; biochemical oxygen demand $\left(B O D_{5}\right)$; chemical oxygen demand basin. For each indicator the number of samples in the observed period (in fact - annually) should be at least four. The value of SCWPI varies from 1 to 16 in waters of different degrees of pollution. The higher value of the index corresponds to the worst water quality. This method allows to divide natural water into five main quality classes depending on its pollution.

For each indicator the frequency of pollution cases $\left(a_{i j}\right)$ is calculated by the formula:

$\alpha_{i j}=n_{i j}^{\prime} / n_{i j} \cdot 100 \%$ 
where:

$n_{i j}^{\prime}$ - number of chemical analysis results for the $i$-th ingredient in the $j$-th observation point, in which their content or value exceeds the corresponding MPC;

$n_{i j}$ - total number of chemical analysis results for the observed period of time for the $i$-th ingredient in the $j$-th river shot.

Particular evaluation score of repeatability $\left(S_{\alpha i j}\right)$ - numerical value from 0 to 4 in the corresponding table - is then determined with Eq. (1).

At the second stage the analysis of MPC excess is carried out, the higher the ratio of detected concentration to MPC, the higher the coefficient is assigned. The calculation is based on the formula:

$\bar{\beta}_{i j}^{\prime}=\sum_{f=1}^{n_{i j}^{\prime}} \beta_{i f j} / n_{i j}^{\prime}$

where:

$\beta_{i f j}=C_{i f j} / \mathrm{MPC}_{i}-$ multiplicity of MPC excess at the $i$-th ingredient in the $f$-th result of chemical analysis for the $j$-th river shot.

By the value of average multiplicity of excess MPC particular score is determined by the multiplicity of $S_{\beta i j}$ excess (numerical value from 0 to 4 in the corresponding table).

The generalized evaluation score $\left(S_{i j}\right)$ is then determined by the formula:

$S_{i j}=S_{\alpha i j} \cdot S_{\beta i j}$

The generalized evaluation score takes into account both the values of the observed concentrations and the frequency of detection of cases of MPC excess for each ingredient.
Then the combinatorial index and specific combinatorial index of water pollution are determined by formulas:

$S_{j}=\sum_{i=1}^{N_{j}} S_{i j}$

where:

$S_{j}$ - combinatorial index of water pollution in the $j$-th water shot;

$N_{j}$ - number of ingredients included in the assessment;

$S_{j}^{\prime}=S_{j} / N_{j}$

where:

$S_{j}^{\prime}$-specific combinatorial index of water pollution in the $j$-th water shot.

At the last stage, the critical indicators of water pollution are determined, which correspond to the following conditions:

- in at least $25 \%$ of the samples in the observed period the ingredient concentration exceeds MPC by five times or more (for some elements - by 10 times or more);

- ingredient concentrations exceed MPC not less than $50 \%$ of the total number of samples in the observed period;

- average ingredient concentrations in the observed period should also be above the maximum permissible.

The total SCWPI value is multiplied by the coefficients of critical indicators (Vishnevetskiy \& Popruzhniy, 2014).

Determination of the concentration in natural water sulphates was produced using classic volumetric titrimetric method. 
Determination of the content of heavy metals, including copper and manganese, was performed using the method of atomic absorption spectrometry with electrothermal atomization.

\section{Results and discussion}

Analysis of natural water samples was carried out by Azovmorinformcenter, Taganrog. At the observation points, natural water sampling was carried out four times a year. The data of state reports (Federal Service for Supervision of Consumer Rights Protection and Human Welfare, 2014, 2015) were analyzed both for the Russian Federation in general and for the Rostov region (free available on the Internet).

From the diagram of SCIWP index distribution (Fig. 2), it is evident that in most cases the water quality in the water intake points of Taganrog is in the range of values corresponding to the water quality class IVa - "dirty".
It is obvious that the quality of water in the point of water intake in the river Mius is worse than in the point of water intake in the river Don: this pattern has been observed for seven years from the nine-year period under consideration. The following critical water quality indicators were noted: sulfates, manganese, copper, molybdenum and zinc, of which the first three indicators were classified as critical most often (Vishnevetskiy \& Popruzhniy, 2015).

In the table statistics on natural water quality in the city's water intake points and statistics showing the dynamics of mortality and primary morbidity of the cardiovascular system is presented: mortality and morbidity statistics are given for Taganrog as a whole, water quality statistics give a quantitative characteristic for the weighted average value entering urban water intakes. Such water quality is classified as contaminated and dirty (Federal State Establishment, 2014).

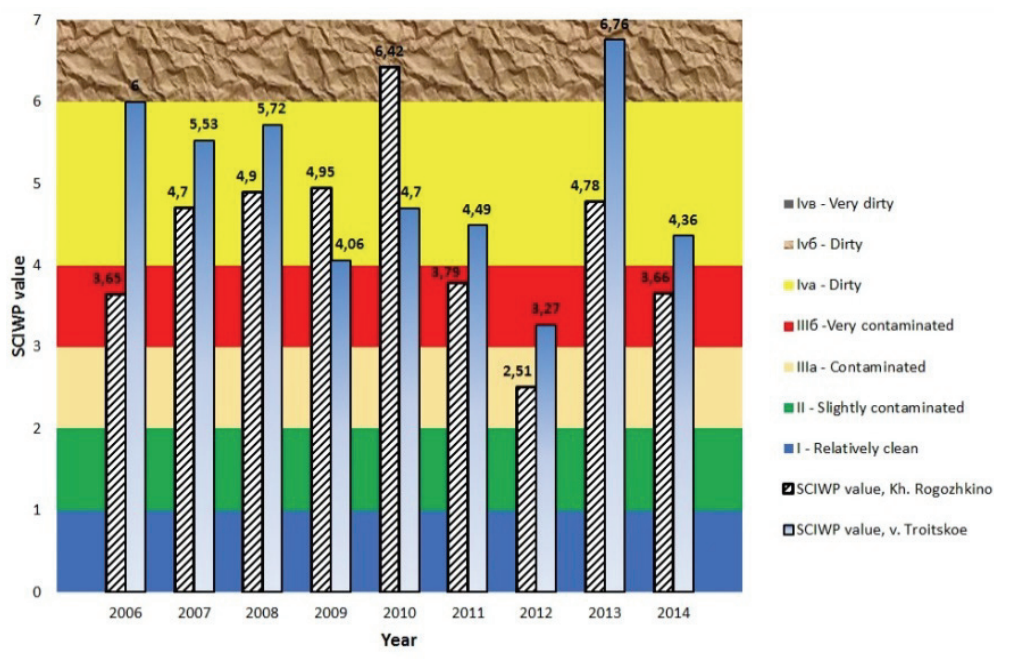

FIGURE 2. SCIWP index dynamics for the period 2006-2014 for Taganrog 
TABLE. Statistics of mortality and primary morbidity due to CVD

\begin{tabular}{|c|c|c|c|}
\hline Year & $\begin{array}{c}\text { Average number of deaths } \\
\text { (per 1,000 people) for Taganrog }\end{array}$ & $\begin{array}{c}\text { Number of first-time cases } \\
\text { (per 1,000 people) for Taganrog }\end{array}$ & SCIWP \\
\hline 2009 & 10.61 & 29.1 & 3.96 \\
\hline 2010 & 10.05 & 30 & 5.57 \\
\hline 2011 & 10.11 & 29.5 & 4.91 \\
\hline 2012 & 9.98 & 30.9 & 3.11 \\
\hline 2013 & 10.34 & 39.4 & 5.70 \\
\hline 2014 & 10.75 & 34.5 & 4.43 \\
\hline
\end{tabular}

During the observed period, the trend was towards increasing of the primary morbidity of CVD in Taganrog (average annual growth rate $+24.57 \%$ ) in 2013 , compared to previous year, the morbidity of registered anemia was increased by $2.06 \%$ (Vishnevetskiy \& Popruzhniy, 2015).

In 2013 the level of primary morbidity increased by $35.4 \%$, the increase in morbidity of child circulatory system in 2013 was $14.19 \%$, which is a significant jump in the dynamics of other diseases. Also from the diagram it is evident that in 2014 the decrease of this indicator was registered (Vishnevetskiy \& Popruzhniy, 2010).

Aanalyzing statistics, we can conclude the following:

- in the period 2009-2010 there was deterioration in the natural water quality, which led to increasing in primary morbidity and mortality;

- in the period 2010-2011 there was improvement in the natural water quality, which led to reduction in the primary morbidity of the population;

- in the period 2011-2012 there was improvement in the natural water quality, which led to reduction in mortality from CVD;
- in the period 2012-2013, there was a sharp deterioration in the natural water quality, which led to equally sharp increasing in primary morbidity and mortality from CVD;

- in the period 2013-2014, on the contrary, there was a sharp improvement in the natural water quality, which led to equally sharp decrease in primary morbidity and mortality from CVD.

To assess the dependence of public health on water quality, the data on primary morbidity and mortality are summarized in the general diagrams, depending on the quantitative evaluation of the SCIWP index (Figs. 3, 4).

It can be seen in Figure 3 that water of "contaminated" class (less than 4 in the $\mathrm{X}$ axis) corresponds to the lowest mortality for a period of time due to cardiovascular diseases; with deterioration of water quality to the category "dirty" (from 4 to 6 in the $\mathrm{X}$ axis) the mortality of the population also increases substantially. In Figure 4 we can observe general tendency to increasing of the primary morbidity of the population with deterioration of water quality. In both cases, the highest quality of water corresponds to the maximum values for mortality and primary morbidity and visible trend of 


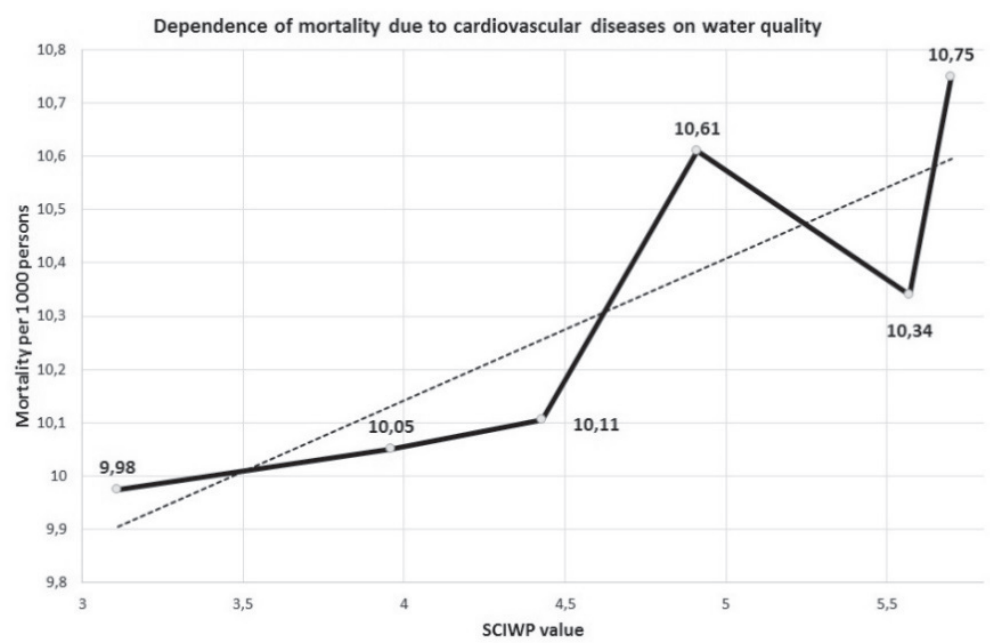

FIGURE 3. Dependence of mortality due to CVD on water quality for the period 2009-2014

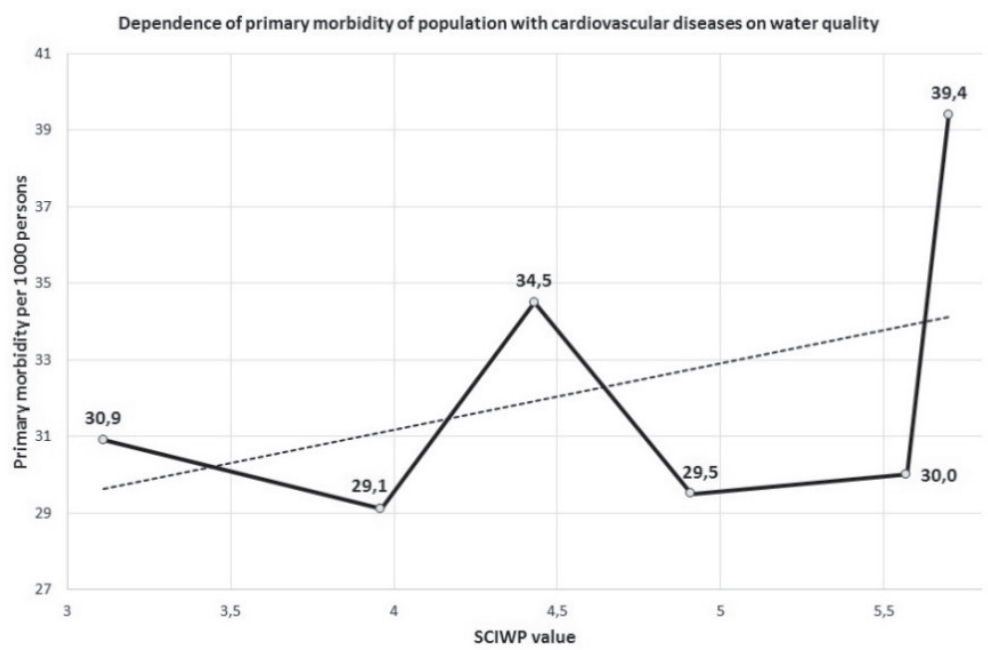

FIGURE 4. Dependence of primary morbidity from CVD on water quality for the period 2009-2014

increasing mortality and morbidity of the population with deteriorating water quality is presented.

Further we consider the impact of "critical indicators" of water quality on public health.

Sulphates. High sulfate concentrations are typical for steppe rivers. This indicates on high hardness and salin- ity of natural water, which directly affects the drinking water. The diagram (Fig. 5) shows that the concentrations of sulphates in natural water are significantly higher than MPC for fishery water basins, but compared to the MPC established by the sanitary standards for drinking water, the natural water in the main water intake point, for most of the period 


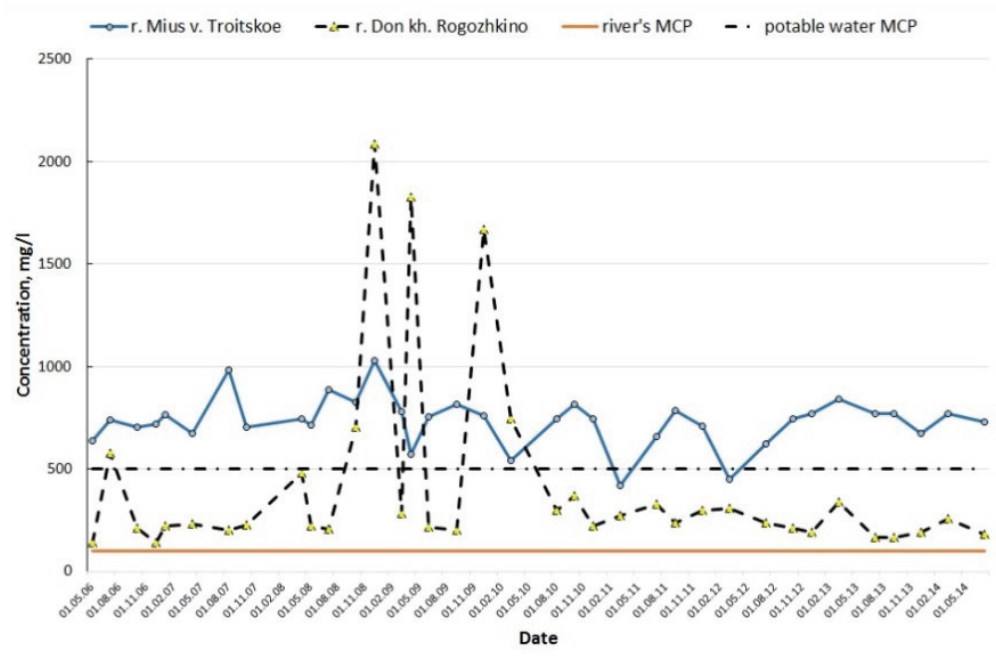

FIGURE 5. The dynamics of sulphate concentration for the period 2006-2014

under consideration, is within the norm (Vishnevetskiy \& Popruzhniy, 2014).

Thus, the natural water in additional water intake of Taganrog in the river Mius, in which the concentrations of sulfates exceed the sanitary norms by a factor of 1.5 to 2 during the whole period, can directly damage the health of a person when used as drinking water, but this harm can not be significant and negatively affect the cardiovascular system.

\section{Copper}

Copper comes to the body mainly with food. Some vegetables and fruits contain between 30 and $230 \mathrm{mg} \cdot \mathrm{g}^{-1}$ of copper. Heat treatment practically does not affect the amount of copper in the products.

As can be seen from the diagram (Fig. 6), the concentrations of heavy metal in water are significantly higher than MPC for fishery river waters. In the river Mius an average of two to five times, only in the second half of 2014 there are two peaks - 15 and $27 \mathrm{MPC}$; in the river Don from two to 10 times and even higher. These facts testify first of all that at such a high copper content in water there will be accumulation of it in aquatic flora (algae, reeds) and river inhabitants of reservoirs (Federal State Establishment, 2014).

Statistics of primary morbidity and mortality shown at Figure 7 are given for Taganrog on average for men and women per 1,000 persons, the concentrations of copper calculated from the hydrochemical analysis of samples of natural water in the areas of both water intakes in Taganrog are averaged by the entry to the city water supply.

As the concentration of copper in the water increases, the mortality and primary morbidity of the population increases, except that the minimum value of the copper concentration considered corresponds to a high mortality value - in this case, there is an effect of lack of metal for the organism (Federal State Establishment, 2014). 


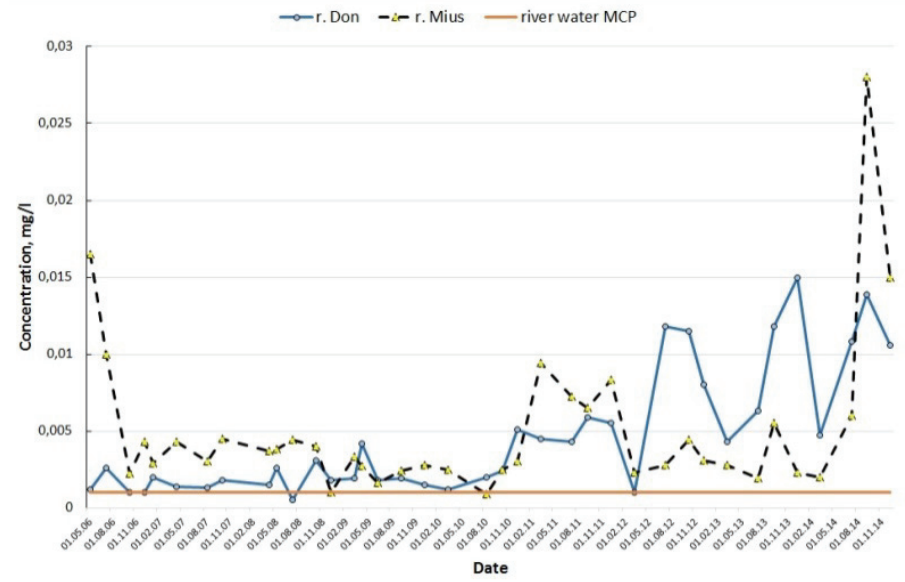

FIGURE 6. Dynamics of copper for the period 2006-2014
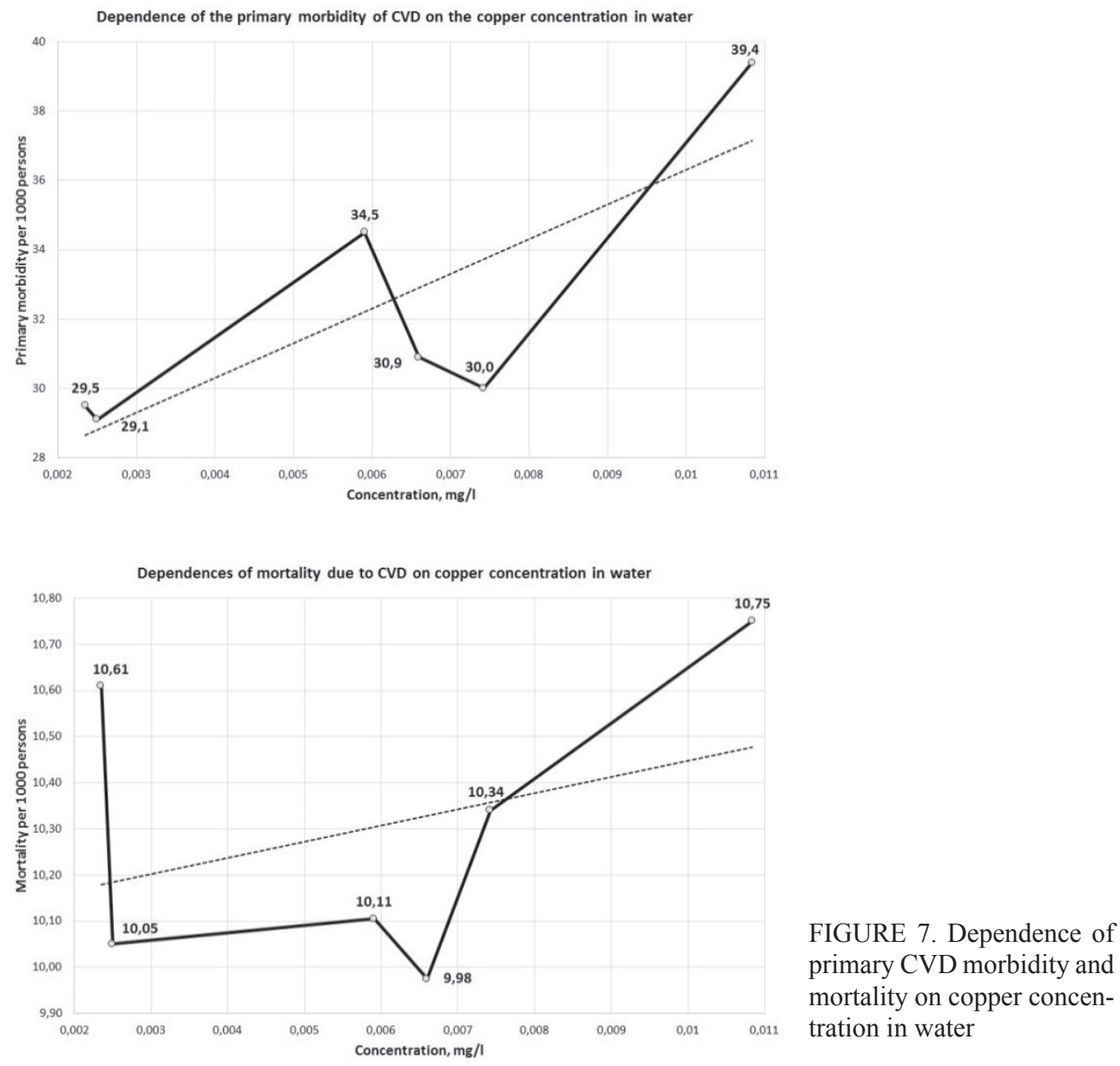


\section{Manganese}

The normal level of manganese entering the body is especially important for people, since manganese has a preventive and even curative effect on CVD. Potassium permanganate solution is able to neutralize the effect of toxins on cells during poisoning, and also improves the process of hematopoiesis. A prolonged deficiency of manganese in the body can lead to negative factors. Manganese overabundance in the body has a much more negative impact on human health. Manganese refers to heavy metals that have a toxic effect on the body (Klimov \& Zhukova, 2013).

The statistics of primary morbidity and mortality shown at Figure 8 are
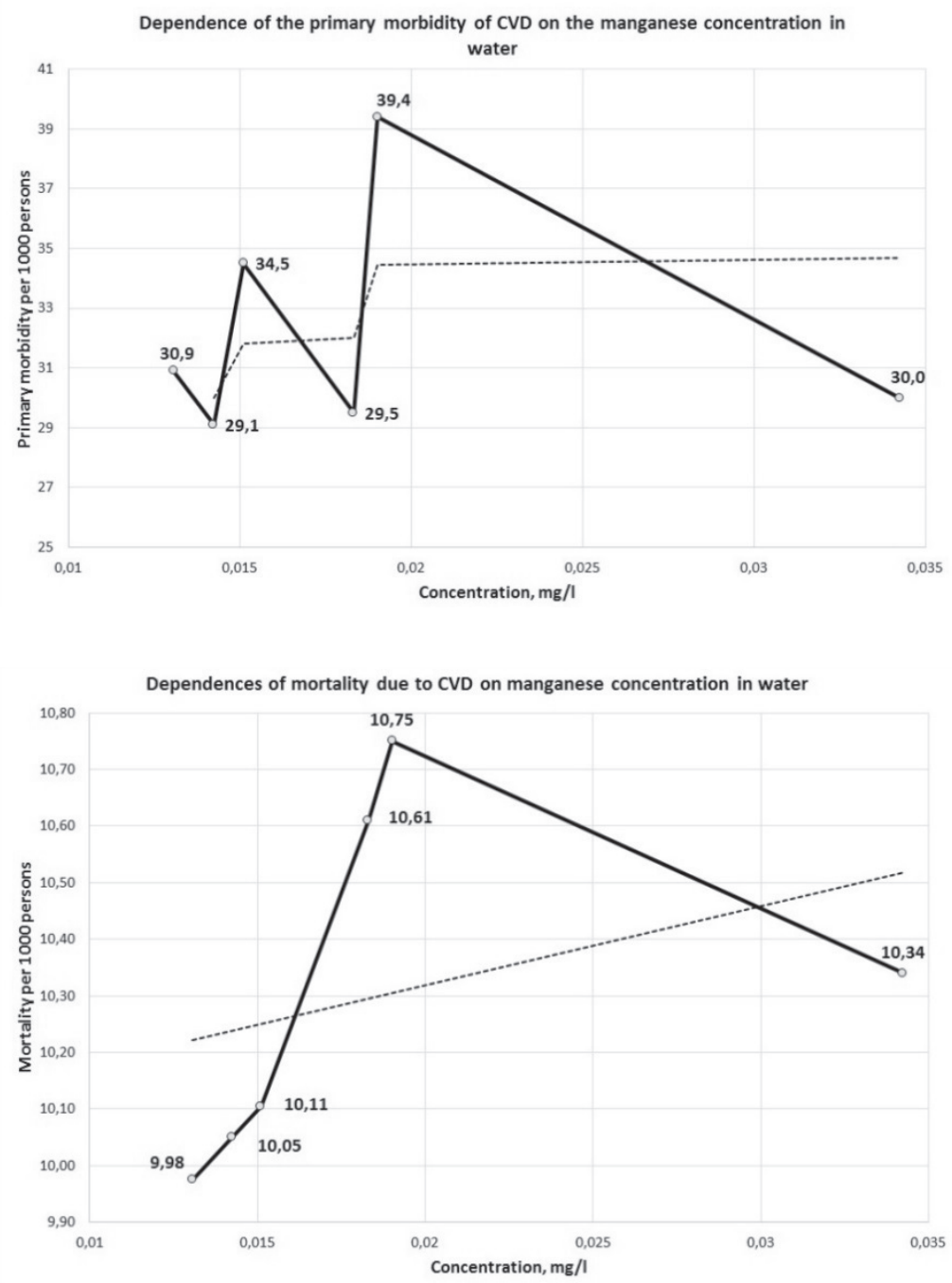

FIGURE 8. Dependence of primary CVD morbidity and mortality on manganese concentration in water 
given for Taganrog on average for men and women per 1,000 persons. Concentrations of manganese were calculated in the same manner as for copper. With an increase in the concentration of manganese in water, there is a tendency to increase mortality and primary morbidity in the population.

Thus, there is a direct relationship between the quality of natural water, the high content of heavy metals in it, and the amount of CVD in the population (Federal Service for Supervision of Consumer Rights Protection and Human Welfare, 2015).

It should be borne in mind that purification of drinking water in urban water supply systems is carried out only as mechanical filtration and hydrobiological protection, therefore heavy metals - both copper and manganese - dissolved in natural water enter drinking water pipelines. In addition, heavy metals are slowly eliminated from the body and serve as a prerequisite for the so-called cumulative effect of the food chain - the increase in the concentration in organisms of subsequent trophic levels. The presence of high concentrations of heavy metals in water leads to their ac- tive absorption by the biological medium, which in turn leads to diseases, both the fish itself and those used for human consumption. In relation to Taganrog, this factor is very significant due to the uniqueness of the Taganrog Gulf as a water basin of fishery importance due to the shallow water and the freshening of sea water, especially in the eastern part of the bay and due to the supply of fresh water from the river. River Don is home to more than 100 species of different fish, which, in turn, are actively consumed by humans (Federal Service for Supervision of Consumer Rights Protection and Human Welfare, 2014). Thus, the concentrations of heavy metals entering the human body when taking fish as food are much higher than the concentrations of metals in water. In terms of the CVD problem of the population this is important, because for the prevention of CVD doctors recommend 2-3 times a week to consume fish (Aldibekova, Aldibekova \& Baysakalova, 2016).

Based on the analysis carried out, system for the prevention of human diseases arising from the negative impact of polluted natural waters is proposed in accordance with the following block diagram (Fig. 9).

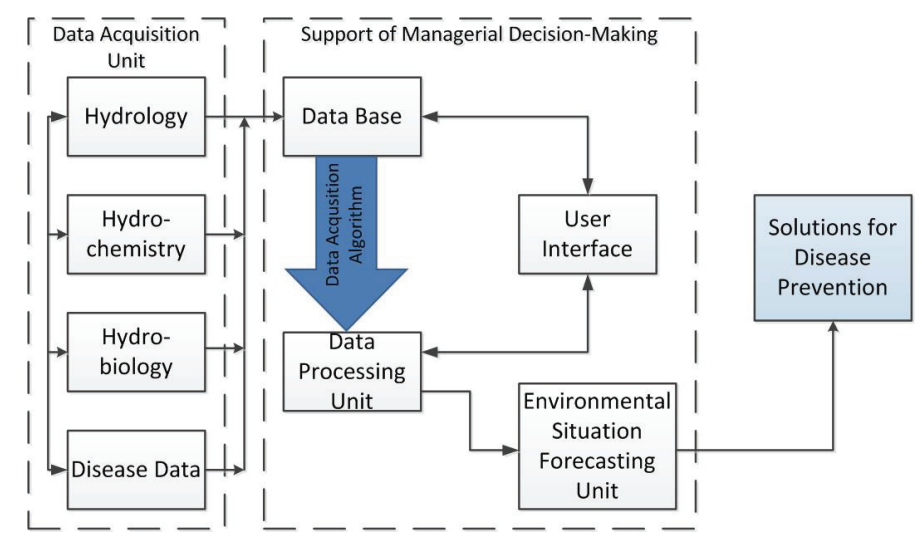

FIGURE 9. Block diagram of the system of human diseases prevention 
System presented on Figure 9 consists of two main units: data acquisition and support. As one can see data flows from several sources (not limited to submitted ones): hydrological, hydrochemical, hydrobiological and medical. In support unit the data base is formed from all streams. According to acquisition algorithms data arrives to processing unit. User interface provides interaction between database, processor and user. Forecasting unit suggest some solution depending on the environmental situation that results in medical decision for dicease prevention.

\section{Conclusions}

The question of connection between consumed water quality and public health was discussed and investigated in numerous research (Monarca, Zerbini, Simonati \& Gelatti, 2003; Catling, Abubakar, Lake, Swift \& Hunter, 2008; Jang et al. 2016; Cui, Iso, Eshak, Maruyama $\&$ Tamakoshi, 2018). Authors of the study (Catling et al., 2008) found significant evidence of an inverse association between magnesium levels in drinking water and cardiovascular mortality. Evidence for calcium remains unclear. In some papers (Jang et al., 2016) authors found out no statistically significant association between water intake and any CVD diseases, in other (Cui et al., 2018) - they did. Problem of influence of heavy metals in water were discussed in (Alissa \& Ferns, 2011; Chowdhury et al., 2018; Rehman, Fatima, Waheed $\&$ Akash, 2018). Water of "contaminated" class corresponds to the lowest mortality due to CVD diseases; water of category "dirty" leads to the substantial- ly increasing of population mortality. As the concentration of copper and manganese in the water increases, the mortality and primary morbidity of the population also increases. Some deviations from this trend only reveal the obtained tendency.

\section{References}

Aldibekova, K.N., Aldibekova, Sh.N. \& Baysakalova, A.Sh. (2016). Features of Influence of Ionizing Heavy Metals on Health of Person. Actual Problems of Humanities and Natural Sciences, 2-6, 5-9.

Alissa, E.M. \& Ferns, G.A. (2011). Heavy metal poisoning and cardiovascular disease. Journal of Toxicology, \#870125. https://doi. org/10.1155/2011/870125

Catling, L.A., Abubakar, I., Lake, I.R., Swift, L. \& Hunter, P.R. (2008). A systematic review of analytical observational studies investigating the association between cardiovascular disease and drinking water hardness. Journal of $J$ Water Health, 6(4), 433-442.

Chowdhury, R., Ramond, A., O'Keeffe, L.M., Shahzad, S., Kunutsor, S.K., Muka, T., ... Di Angelantonio, E. (2018). Environmental toxic metal contaminants and risk of cardiovascular disease: systematic review and meta-analysis. BMJ, 362, k3310 https:/doi. org/10.1136/bmj.k3310

Cui, R., Iso, H., Eshak, E., Maruyama, K., \& Tamakoshi, A. (2018). Water intake from foods and beverages and risk of mortality from CVD: The Japan Collaborative Cohort (JACC) Study. Public Health Nutrition, 21(16), 3011-3017.

Federal Service for Supervision of Consumer Rights Protection and Human Welfare (2014). Report on the state of sanitary and epidemiological welfare of the population for 2014. Rostov: Center of hygiene and epidemiology in the Rostov region. Retrieved from: http:/www.61.rospotrebnadzor.ru/ files/35 ГД_2014_\%20PO.zip.

Federal Service for Supervision of Consumer Rights Protection and Human Welfare. (2015). State report. On the state of sanitary 
and epidemiological welfare of the population in the Russian Federation in 2014. Rostov: Center of hygiene and epidemiology in the Rostov region. Retrieved from: https:// vk.kiwi/dj0iY

Federal State Establishment (2014). Information Bulletin on the state of water bodies, bottom, shores, their morphometric features, water protection zones, quantitative and qualitative indicators of water resources, the state of water management systems, including hydraulic structures in the area of activity of the Federal state establishment. Taganrog: Azovmorinformcenter. Retrieved from: http://azovinform.ru/content/menu/132/ inf_bul_2014.pdf.

Jang, S., Cheon, C., Jang, B.H. Park, S., Oh, S.M., Shin, Y.C. \& Ko, S.G. (2016). Relationship Between Water Intake and Metabolic/Heart Diseases: Based on Korean National Health and Nutrition Examination Survey. Osong Public Health and Research Perspectives, 7(5), 289-295.

Klimov, S.V. \& Zhukova, A.G. (2013). Influence of manganese on human and animal organism. In Materials of the XLVIII scientificpractical conference "Hygiene, health care organization and occupational pathology" (pages 33-36).

Kouroutou, P., Hadjistavrou, K., Linos, A. \& Kales, S. (2012). The Effects of Occupational Heavy Metal Exposure on Morbidity and Mortality. Archives of Hellenic Medicine, 29(1), 70-76.

Monarca, S., Zerbini, I., Simonati, C. \& Gelatti, U. (2003). Drinking water hardness and chronic degenerative diseases. II. Cardiovascular diseases. Annali di Igiene, 15(1), 41-56.

Rehman, K., Fatima, F., Waheed, I. \& Akash, M. (2018). Prevalence of exposure of heavy metals and their impact on health consequences. Journal of Cellular Biochemistry, 119, 157-184.

Vishnevetskiy, V.Yu. \& Popruzhniy, V.M. (2010). Assessment of copper content in water and bottom sediments of the Azov sea. SFedU News. Technical Science, 9(110), 117-122.

Vishnevetskiy, V.Yu. \& Popruzhniy, V.M. (2014). Assessment of water quality in water intakes of Taganrog on hydrochemical indicators. Don Engineering Bulletin, 4-2(32), 16.
Vishnevetskiy, V.Yu., Popruzhniy, V.M. (2015). Assessment of the impact of manganese content in natural water on human health in water intakes of Taganrog. Don Engineering Bulletin, 4-2(39), 24.

\section{Summary}

Investigations of the impact of polluted natural waters on cardiovascular diseases and development of integrated prevention system. The aim of this study was to establish the correlation between natural water pollutions and the prevalence of heart diseases. We analyzed the data from the 2014 Federal Service Report on the state of sanitary and epidemiological welfare of the population. The correlation analysis of data on mortality and primary morbidity of the population was carried out, the correlation between the quality of natural water and cardiovascular diseases of the population was established. The complex method of water quality assessment according to the data of hydrochemical monitoring of the Azov Sea and rivers flowing into it were used in the investigation, the influence of the main pollutants such as copper and manganese on the dynamics of cardiovascular diseases according to mortality and primary morbidity for the population of Taganrog was considered. As conclusion we can state that statistical association between water intake and heart diseases exists in the region of analysis. However, further studies on water intake are needed to confirm our findings.

\section{Authors' address:}

Vyacheslav Vishnevetskiy

Southern Federal University

Shevchenko, 2, Building E, room E-307, 347922,

Taganrog

Rostovskaya oblast, Russia,

e-mail: vuvishnevetsky@mail.ru

Vladislav Popruzhniy

Azovmorinformcenter

Instrumental'naya 48, Taganrog

Rostovskaya oblast

Russia, 347923 